\title{
PROCEEDINGS OF THE \\ British Pharmacological \\ Society
}

15th-17th September, 1975

THE UNIVERSITY OF CAMBRIDGE

\section{COMMUNICATIONS}

In communications with more than one author, an asterisk (*) denotes the one intending to present the work.

Prostaglandin $D_{1}$ inhibits the increase in vascular permeability in rat skin produced by prostaglandin $E_{1}, E_{2}$ and $D_{2}$

\section{R.J. FLOWER \& W.P. KINGSTON*}

Department of Pharmacology, Wellcome Research Laboratories, Beckenham, Kent

Increased vascular permeability is induced by intradermal injection of prostaglandin $(\mathrm{PG}) \mathrm{E}_{1}, \mathrm{E}_{2}$
(Crunkhorn \& Willis, 1971a) or $\mathrm{D}_{2}$ (Kingston, Flower \& Harvey, 1975). PGF $2 \alpha$ diminishes the cutaneous vascular effects of $\mathrm{PGE}_{1}, \mathrm{PGE}_{2}$ (Crunkhorn \& Willis, 1971b) histamine or bradykinin (Thomas \& West, 1974). PGD $_{1}$ also reduces the cutaneous vascular effects of prostaglandins $E_{1}, E_{2}$ and $D_{2}$ in rat skin. We have compared the effects of $P G_{1}$ and $F_{2 \alpha}$ on increased vascular permeability, as measured by extravasation of ${ }^{125} \mathrm{I}$ albumin.

Table 1 Extravasation of ${ }^{125} /$-albumin at the sites of intradermal injection $(n=10)$

\begin{tabular}{|c|c|c|c|}
\hline & & \multicolumn{2}{|c|}{ Counts in lesion * } \\
\hline & & \multicolumn{2}{|c|}{ Counts in $10 \mu$ blood } \\
\hline & Alone & $+0.5 \mu g P G D_{1}$ & $+0.5 \mu g P G F_{2 \alpha}$ \\
\hline $\begin{array}{l}100 \mathrm{ng} \mathrm{PGE}_{1} \\
1 \mu \mathrm{g} \mathrm{PGE}_{2} \\
1 \mu \mathrm{g} \mathrm{PGD}_{2} \\
1 \mu \mathrm{g} \text { Bradykinin } \\
10 \mu \mathrm{g} \text { Histamine } \\
0.5 \mu \mathrm{g} \mathrm{PGD}_{1} \\
0.5 \mu \mathrm{g} \mathrm{PGF}_{2 \alpha} \\
\text { Saline }\end{array}$ & $\begin{array}{r}9.0 \\
28.8 \\
10.7 \\
6.1 \\
3.6 \\
0.4 \\
0.3 \\
0.3\end{array}$ & $\begin{array}{r}2.7 \\
10.7 \\
3.8 \\
5.9 \\
3.7\end{array}$ & $\begin{array}{l}2.9 \\
8.2 \\
3.0 \\
4.6 \\
1.3\end{array}$ \\
\hline
\end{tabular}

* Values corrected for a background of 1.6. 
Olac rats (approximately $200 \mathrm{~g}$ weight) were lightly anaesthetized with ether and injected intravenously with ${ }^{125} \mathrm{I}$ albumin $(5 \mu \mathrm{Ci})$ and Evans blue $(40 \mathrm{mg} / \mathrm{kg})$. Drugs were then injected in $0.1 \mathrm{ml}$ saline intradermally into the shaved abdominal skin. Twenty minutes later, the animals were killed and the skin removed. Discs of skin were excised which included the whole of the lesion (as indicated by blueing). The excised skin was wrapped in a single layer of parafilm and the radioactivity measured in a gamma counter. The radioactivity in $10 \mu \mathrm{l}$ of blood was measured as a reference.

Intradermal injection of $P G E_{1}, E_{2}$ and $D_{2}$ produced increases in vascular permeability. These effects were reduced by admixture with PGD $_{1}$ (Table 1).

PGD $_{1}$ did not modify the increased vascular permeability induced by histamine or bradykinin, as would be expected if it was acting through vasoconstriction. PGF $_{2 \alpha}$ reduced the effects of histamine and bradykinin as well as prostaglandins $E_{1}, E_{2}$ and $D_{2}$ showing that its effect was less specific than that of $P G D_{1}$. These results suggest a role for $\mathrm{PGD}_{1}$ and $\mathrm{PGF}_{2 \alpha}$ as modulators of skin inflammation.

\section{References}

CRUNKHORN, P. \& WILLIS, A.L. (1971a). Cutaneous reactions to intradermal prostaglandins. $B r . J$. Pharmac., 41, 49-56.

CRUNKHORN, P. \& WILLIS, A.L. (1971b). Interaction between prostaglandins $\mathrm{E}$ and $\mathrm{F}$ given intradermally in the rat. Br. J. Pharmac., 41, 507-512.

KINGSTON, W.P., FLOWER, R.J. \& HARVEY, E.A. (1975). Inflammatory responses to prostaglandin $D_{2}$ in rat and human skin. In press.

THOMAS, G. \& WEST, G.B. (1974). Prostaglandins, kinin and inflammation in the rat. Br. J. Pharmac., 50, 231-235.

\section{A comparison of the histopathological effects of anaphylatoxin (AT) and prosta- glandins $E_{2}\left(\mathrm{PGE}_{2}\right)$ and $F_{2 \alpha}\left(\mathrm{PGF}_{2 \alpha}\right)$ in guinea-pig lungs}

\section{A.C. SACKEYFIO (introduced by R. HICKS)}

Department of Pharmacology, University of Science and Technology, Kumasi, Ghana

In a previous study it was shown that AT induced the release of a substance with prostaglandin-like activity in isolated perfused guinea-pig lungs (Sackeyfio, 1972). Other investigations have also shown that the complex effects of AT in the guinea-pig lead not only to the release of the bronchoconstrictor substance, histamine (Sackeyfio, 1971) but also to the stimulation of adrenergic mechanisms which are predominantly bronchodilator (Hicks \& Sackeyfio, 1971). However, the dominant symptomatic feature of (AT) administration in the guinea-pig is intense respiratory distress. The present investigation was undertaken with the view that a comparison of the histopathological effects of AT with those of known or suspected mediators of AT activity might provide further elucidation of the mechanisms involved in AT activity.

AT was prepared as previously reported (Sackeyfio, 1971). Groups of guinea-pigs were anaesthetized with pentobarbitone $(60 \mathrm{mg} / \mathrm{kg}$ i.p. $)$ and injected i.v. with one or other of the following: AT $(0.5 \mathrm{ml} / \mathrm{kg})$; rat native serum $(0.5 \mathrm{ml} / \mathrm{kg})$, histamine $(20 \mu \mathrm{g} / \mathrm{kg}), \mathrm{PGE}_{2}(1 \mathrm{mg} / \mathrm{kg})$ or $\mathrm{PGF}_{2 \alpha}(1 \mathrm{mg} / \mathrm{kg})$. The lungs were isolated, fixed in $10 \%$ buffered formalin for $24 \mathrm{~h}$, embedded in wax, sections were stained with haematoxylin and eosin and examined microscopically. Lungs from untreated guinea-pigs were similarly prepared for comparison.

Examination of the slides showed that AT, histamine, $\mathrm{PGE}_{2}$ and $\mathrm{PGF}_{2} \alpha$ induced varying degrees of bronchoconstriction and thickening of the bronchial muscle (the order of intensity being $\mathrm{AT}>$ histamine $=\mathrm{PGF}_{2}>\mathrm{PGE}_{2}$ ). Intense peribronchial oedema and vasoconstriction were observed only in the AT- and PGF 2 treated animals, but not in the other groups of guinea-pigs. $\mathrm{AT}$, histamine and $\mathrm{PGF}_{2} \alpha$ induced perivascular oedema, thickening of the vascular wall and intense emphysema but $\mathrm{PGE}_{2}$ had no such effects. Neither the untreated nor the native serum treated animals showed any of these histopathological effects.

The results of this study showed that the histopathological effects of AT were mimicked entirely by $\mathrm{PGF}_{2 \alpha}$, partially by histamine but hardly at all, by $\mathrm{PGE}_{2}$.

Mepyramine $(0.5-4 \mathrm{mg} / \mathrm{kg})$ abolished the effects of histamine but only partially reduced the AT-induced effects. The AT-induced oedema was 